\title{
CARACTERÍSTICAS QUALITATIVAS DE CULTIVARES DE CEBOLA NO SUL DE MINAS GERAIS
}

\author{
Qualitative characteristics of onion cultivars in southern Minas Gerais State
}

Silvio Júlio de Rezende Chagas ${ }^{1}$, Geraldo Milanez de Resende ${ }^{2}$, Lair Victor Pereira ${ }^{1}$

\begin{abstract}
RESUMO
Com o objetivo de determinar a composição físico-química e química de cultivares de cebola (Allium cepa L.), conduziu-se um ensaio na Fazenda Experimental de Lavras da EPAMIG, Lavras-MG, no período de março a setembro de 1995. O delineamento experimental foi de blocos ao acaso com quatro repetições e 6 tratamentos, constituídos pelas cultivares Baia Periforme, Crioula, Granex 33, Pira Ouro, Jubileu e Texas Grano 502. Após a cura, avaliaram-se o pH, sólidos solúveis e totais $(\%)$, acidez titulável (\%), ácido pirúvico ( $\mu \mathrm{mol} / \mathrm{g})$, açúcares totais, redutores e não-redutores (\%) e índice industrial dos bulbos. As cultivares Crioula, Baia Periforme, Pira Ouro e Jubileu apresentaram as maiores concentrações de sólidos totais e solúveis. A acidez mais elevada foi observada nas cultivares Crioula $(0,370 \%)$ e Pira Ouro $(0,315 \%)$. Os maiores índices industriais foram apresentados pelas cultivares Crioula $(0,87)$ e Baia Periforme $(0,75)$, e os menores, pelas cultivares Texas Grano 502 $(0,51)$ e Granex $33(0,32)$.
\end{abstract}

Termos para indexação: Allium cepa, sólidos solúveis e totais, pH, acidez, índice industrial.

\section{ABSTRACT}

This study was carried out from March to September of 1995, in the Experimental Field of EPAMIG, Lavras-MG, Brazil, with the objective of determining the physico-chemical and chemical composition of onions from different cultivars (Allium cepa L.). The experimental design was completely randomized blocks with four repetitions and six cultivars as follow: Baia Periforme, Crioula, Granex 33, Pira Ouro, Jubileu and Texas Grano 502. After the cure it was evaluated the pH, soluble and total solids $(\%)$, titrate acidity $(\%)$, pyruvic acid $(\mu \mathrm{mol} / \mathrm{g})$, total sugar, reducers and non reducers $(\%)$ and industrial index. The cultivars Crioula, Baia Periforme, Pira Ouro and Jubileu showed the largest concentrations of total and soluble solids. The highest acidity indexes were observed in the cultivars Crioula $(0.370 \%)$ and Pira Ouro $(0.315 \%)$. The largest industrial indexes were found in the cultivars Crioula (0.87) and Baia Periforme (0.75), and the smallest ones in the cultivars Texas Grano 502 (0.51) and Granex 33 (0.32).

Index terms: Allium cepa, soluble solids content, total solids content, $\mathrm{pH}$, industrial index.

(Recebido para publicação em 15 de janeiro de 2003 e aprovado em 3 de abril de 2003)

\section{INTRODUÇÃO}

A alta perecibilidade da cebola tem limitado seu período de comercialização e proporcionado altas perdas pós-colheita. Nos Estados Unidos, grande parte da produção de cebolas tem sido industrializada nas formas cozida, picles congelados, desidratadas (pó e flocos), essência (óleo de cebola), bulbos enlatados (conserva), e desidratada a frio (freeze dried). No Brasil, atualmente, é mais fácil encontrála industrializada na forma de flocos desidratados, creme de cebola, picles e bulbos enlatados em conserva (SOUZA e RESENDE, 2002). A industrialização de cebola ainda é pouco praticada no Brasil; entretanto, há pequena produção de cebola desidratada, na forma de pó ou de flocos e como picles (FILGUEIRA, 2000).
Uma das alternativas para prolongar é armazenar a frio os bulbos ou industrializar. Segundo algumas estimativas, o volume de cebola industrializada no País é em torno de $6 \%$ da produção nacional (DEBARBA et

al., 1998). A utilização de cebola processada é feita principalmente por empresas que fabricam produtos desidratados, como sopas instantâneas, caldos, preparações básicas, condimentos, molhos e na indústria carnes e enlatados (DEBARBA et al., 1998; SOUZA e RESENDE, 2002).

A qualidade pós-colheita relaciona-se ao conjunto de atributos ou propriedades que tornam os produtos agrícolas apreciados como alimento. Esses atributos, por sua vez, dependem do mercado de destino, como armazenamento, consumo "in natura" ou processamento. Entre as características físico-químicas utilizadas para avaliar a qualidade pós-colheita de hortaliças, destacam-se o teor de

1. Engenheiro Agrônomo, M.Sc., pesquisador da EPAMIG, Caixa Postal 176, 37200-000 - Lavras, MG.

2. Engenheiro Agrônomo, M.Sc., pesquisador da Embrapa Semi-Árido, Caixa Postal 23, 56300-970 -Petrolina, PE. 
sólidos solúveis, a acidez total titulável e o $\mathrm{pH}$ (CHITARRA, 1994). Uma das características mais importantes da cebola para a industrialização, e em particular para a produção de desidratados, é o seu teor de sólidos totais. Esse teor é grandemente dependente da cultivar e do clima; porém, deve ser o maior possível (FEIMBERG, 1973; CARVALHO et al., 1987).

Uma vez demonstrado que o grau de pungência é proporcional ao teor de ácido pirúvico formado, a determinação desse ácido nos extratos de cebola é um dos meios mais simples para se medir a intensidade da pungência, que é um fator muito importante na escolha da matéria-prima, pois quanto maior, mais pungente é o sabor e aroma do produto acabado, o que é, aliás, desejado pelos consumidores. A determinação do ácido pirúvico como medidor do sabor e aroma em cebola é relatado por Schwimmer e Weston (1961).

Os açúcares presentes no alho e cebola são importantes na qualidade comestível deles. É importante que se determine o teor de sólidos solúveis, pois é nessa fração que se encontram os açúcares responsáveis, em parte, pelo sabor. Os açúcares presentes em cebolas são glicose, frutose e sacarose, juntamente com uma série de oligossacarídeos (CARVALHO et al., 1987).

Os açúcares solúveis presentes no suco ou polpa são responsáveis pelo sabor característico de cada hortaliça, em que o grau de "doçura" é função do aumento da concentração de sólidos. A acidez titulável total, relacionada com teores dos ácidos orgânicos presentes no suco ou polpa, aliada aos teores de sólidos solúveis, é mais uma característica para se avaliar a qualidade póscolheita das hortaliças. $\mathrm{O}$ pH é um indicativo de sabor de uma hortaliça, tendo uma relação inversa com a acidez. Contudo, a capacidade-tampão de alguns sucos permite que ocorram grandes variações na acidez titulável, sem variações apreciáveis no pH (CHITARRA e CHITARRA, 1990).

Com o presente trabalho objetivou-se determinar a composição físico-química e química de diferentes cultivares de cebola sob as condições de cultivo da região sul de Minas Gerais, com a finalidade de indicar aquelas mais adequadas para industrialização.

\section{MATERIAL E MÉTODOS}

O experimento foi instalado no período de abril a setembro de 1995, na Fazenda Experimental de Lavras-FELA, da EPAMIG, situada a $21^{\circ} 14^{\prime}$ de latitude sul, $45^{\circ} 00^{\prime}$ de longitude a oeste de Greenwich, e a uma altitude de $910 \mathrm{~m}$. O clima da região é caracterizado por temperatura média anual que varia de $15,8^{\circ} \mathrm{C}$ no mês mais frio, a $22,1^{\circ} \mathrm{C}$, no mês mais quente; a precipitação média anual é de $1.529,7 \mathrm{~mm}$ e a umidade relativa do ar é de 76,2\% (CASTRO NETTO et al., 1980; BRASIL, 1992).

O delineamento experimental foi de blocos ao acaso com quatro repetições e 6 tratamentos, constituídos das cultivares Granex, Texas Grano 502, Crioula, Pira Ouro, Baia Periforme e Jubileu. As parcelas foram constituídas de seis fileiras de 5,0 x 1,2 m, sendo consideradas como área útil as quatro fileiras centrais, retirando-se uma planta em cada extremidade $\left(3,84 \mathrm{~m}^{2}\right)$, no espaçamento de $0,20 \times 0,10 \mathrm{~m}$.

A adubação básica por hectare constitui-se de $20 \mathrm{~kg}$ de $\mathrm{N}$ (sulfato de amônio), $126 \mathrm{~kg}$ de $\mathrm{P}_{2} \mathrm{O}_{5}$ (superfostato simples), $116 \mathrm{~kg}$ de $\mathrm{K}_{2} \mathrm{O}$ (cloreto de potássio), 4,5 $\mathrm{kg}$ de $\mathrm{Mg}$ (sulfato de magnésio), $2 \mathrm{~kg}$ de $\mathrm{Zn}$ (sulfato de zinco) e 1,65 kg de B (bórax), aplicados no plantio. Sendo realizada uma cobertura aos 45 dias após o plantio na dose de $30 \mathrm{~kg} / \mathrm{ha}$ de $\mathrm{N}$ (sulfato de amônio). Os tratos culturais e controle de pragas e doenças foram realizados de acordo com as recomendações regionais para a cultura e as irrigações realizadas por aspersão duas vezes por semana, quando necessárias, até 15 dias antes da colheita.

O transplantio das mudas foi realizado aos 50 dias após a semeadura, e as irrigações, quando necessárias, foram realizadas por aspersão convencional. A colheita foi efetuada quando mais de $70 \%$ das plantas já se encontravam acamadas. As plantas colhidas foram submetidas ao processo de cura, ficando por três dias expostas ao sol e 30 dias à sombra, a uma temperatura média de $20,8^{\circ} \mathrm{C}$ e umidade relativa do ar de $52 \%$, efetuando-se, em seguida, o corte da parte aérea e raízes (toalete).

Avaliaram-se as seguintes características após o processo de cura do bulbos: $\mathrm{pH}$, sólidos solúveis e totais (\%), acidez titulável (\% ácido pirúvico), ácido pirúvico $(\mu \mathrm{mol} / \mathrm{g})$, açucares totais, redutores e não-redutores (\%). Os sólidos totais foram determinados segundo técnica preconizada pela AOAC (1990), e os sólidos solúveis, determinados por refratometria, utilizando o refratômetro de bancada marca $\mathrm{ABBE}$, segundo técnica descrita pela AOAC (1990). Os açúcares redutores, nãoredutores e totais foram extraídos de acordo com a técnica descrita na AOAC (1990) e identificados pelo método de Somogy, modificado por Nelson (1944). A acidez titulável total foi determinada segundo técnica descrita pela AOAC (1990), sendo expressa em porcentagem de ácido pirúvico. $\mathrm{O} \mathrm{pH}$ foi estimado pelo método 
potenciométrico em eletrodo combinado de vidro. $\mathrm{O}$ teor de ácido pirúvico foi determinado de acordo com Schimmer e Weston (1961). O índice industrial foi dado pela seguinte fórmula: $\mathrm{I}_{\mathrm{i}}=$ Sólidos totais $\mathrm{x}$ ácido pirúvico/100, de acordo com Carvalho (1993).

Os dados foram submetidos à análise de variância das características avaliadas, aplicando-se o teste de Tukey a 5\% de probabilidade, para comparação das médias, segundo metodologia descrita por Gomes (1990).

\section{RESULTADOS E DISCUSSÃO}

Para sólidos solúveis e totais, sobressaíram-se com maiores teores as cultivares Pira Ouro, Crioula, Baia Periforme e Jubileu, com variações de 10,35 a $10,60 \%$, não mostrando diferenças significativas entre si, sendo o pior desempenho apresentado pelas cultivares Texas Grano 502 e Granex 33 (Tabela 1). Resultados similares foram apresentados para sólidos totais. Segundo Carvalho (1980), o teor de sólidos totais em cebolas varia de 5 a $20 \%$. O alto teor de sólidos totais está ligado à alta pungência e à boa qualidade de armazenamento dos bulbos. Paula et al. (1993) verificaram para a cultivar Baia Periforme, em média, 11,70 e $12,33 \%$ de sólidos totais e solúveis, respectivamente.

A acidez mais elevada foi encontrada nas cultivares Crioula e Pira Ouro, com 0,370 e 0,315\%, seguidas das cultivares Jubileu e Baia Periforme, com 0,308 e $0,305 \%$, respectivamente (Tabela 1 ). Os menores va- lores foram verificados nas cultivares Texas Grano 502 e Granex 33, com 0,190 e 0,195\%, respectivamente. Elevada acidez é desejável para a industrialização das cebolas, uma vez que, sendo essa expressa em porcentagem do ácido pirúvico, e esse utilizado para medir grau de pungência (sabor e aroma), o bulbo a ser desidratado deve conter um alto teor de pungência, uma vez que basicamente é utilizado como agente aromatizante e que parte dessa pungência é perdida durante o processamento. A acidez titulável relacionase com os teores dos ácidos orgânicos presentes no suco ou polpa, aliada aos teores de sólidos solúveis, é uma característica importante para se avaliar a qualidade póscolheita das hortaliças (CHITARRA e CHITARRA, 1990).

Houve uma pequena variação no pH (Tabela 1) entre as cultivares, apresentando-se com menores valores a cultivar Texas Grano $502(5,06)$ e com valores mais elevados a cultivar Jubileu $(5,24)$ e a Pira Ouro $(5,23)$. Para os teores de ácido pirúvico (Tabela 2), constatou-se que os maiores teores foram encontrados nas cultivares Crioula $(6,66 \mu \mathrm{mol} / \mathrm{g})$ e Baia Periforme $(5,93 \mu \mathrm{mol} / \mathrm{g})$, que não mostraram diferenças significativas entre si, e os menores na cultivar Granex 33 $(3,06 \mu \mathrm{mol} / \mathrm{g})$. Foi demonstrado que o grau de pungência da cebola é proporcional ao teor de ácido pirúvico formado. Segundo Feimberg (1973), quanto maior a pungência da matéria-prima, mais pungente é o produto, característica desejada pelos consumidores.

TABELA 1 - Sólidos solúveis e totais, acidez titulável e pH de cultivares de cebola. EPAMIG, Lavras, MG, $1995^{1}$.

\begin{tabular}{|c|c|c|c|c|}
\hline Cultivares & $\begin{array}{c}\text { Sólidos solúveis } \\
(\%)\end{array}$ & $\begin{array}{c}\text { Sólidos totais } \\
(\%)\end{array}$ & $\begin{array}{l}\text { Acidez titulável } \\
\text { (\% ácido pirúvico) }\end{array}$ & pH \\
\hline Pira Ouro & $10,60 \mathrm{a}$ & $12,99 \mathrm{a}$ & $0,315 \mathrm{a}$ & $5,23 \mathrm{a}$ \\
\hline Crioula & $10,58 \mathrm{a}$ & $13,10 \mathrm{a}$ & $0,370 \mathrm{a}$ & $5,08 \mathrm{bc}$ \\
\hline Baia Periforme & $10,42 \mathrm{a}$ & $12,68 \mathrm{a}$ & $0,305 \mathrm{~b}$ & $5,11 \mathrm{~b}$ \\
\hline Jubileu & $10,35 \mathrm{a}$ & $12,80 \mathrm{a}$ & $0,308 \mathrm{~b}$ & $5,24 \mathrm{a}$ \\
\hline Granex 33 & $8,58 \mathrm{~b}$ & $10,55 \mathrm{~b}$ & $0,195 \mathrm{c}$ & $5,05 \mathrm{c}$ \\
\hline Texas Grano 502 & $8,16 \mathrm{~b}$ & $10,06 \mathrm{~b}$ & $0,190 \mathrm{c}$ & $5,06 \mathrm{bc}$ \\
\hline C.V. $(\%)$ & 3,98 & 5,17 & 4,21 & 0,38 \\
\hline
\end{tabular}

${ }^{1}$ Médias seguidas pela mesma letra nas colunas não diferem entre si pelo teste de Tukey a $5 \%$ de probabilidade. 
TABELA 2 - Ácido pirúvico, Açucares totais, redutores e não-redutores e índice industrial de cultivares de cebola. EPAMIG, Lavras, MG, $1995^{1}$.

\begin{tabular}{lccccc}
\hline \multirow{2}{*}{ Cultivares } & $\begin{array}{c}\text { Ácido pirúvico } \\
(\boldsymbol{\mu m o l} / \mathbf{g})\end{array}$ & \multicolumn{3}{c}{ Açucares (\%) } & $\begin{array}{c}\text { Índice } \\
\text { Industrial }\end{array}$ \\
\cline { 3 - 5 } & $6,66 \mathrm{a}$ & $4,39 \mathrm{~b}$ & $2,53 \mathrm{bc}$ & $1,76 \mathrm{~b}$ & $0,87 \mathrm{a}$ \\
\hline Crioula & $5,93 \mathrm{ab}$ & $5,64 \mathrm{a}$ & $2,24 \mathrm{c}$ & $3,23 \mathrm{a}$ & $0,75 \mathrm{ab}$ \\
Baia Periforme & $5,26 \mathrm{~b}$ & $6,17 \mathrm{a}$ & $2,43 \mathrm{c}$ & $3,55 \mathrm{a}$ & $0,69 \mathrm{~b}$ \\
Pira Ouro & $5,16 \mathrm{~b}$ & $5,82 \mathrm{a}$ & $2,84 \mathrm{bc}$ & $2,91 \mathrm{a}$ & $0,66 \mathrm{~b}$ \\
Jubileu & $5,08 \mathrm{~b}$ & $4,63 \mathrm{~b}$ & $3,10 \mathrm{ab}$ & $1,44 \mathrm{bc}$ & $0,51 \mathrm{c}$ \\
Texas Grano 502 & $3,06 \mathrm{c}$ & $4,34 \mathrm{~b}$ & $3,55 \mathrm{a}$ & $0,74 \mathrm{c}$ & $0,32 \mathrm{~d}$ \\
Granex 33 & 8,81 & 7,78 & 9,70 & 10,03 & 10,24 \\
\hline C.V. $(\%)$ & & & Redutores & Não redutores & \\
\hline
\end{tabular}

${ }^{1}$ Médias seguidas pela mesma letra nas colunas não diferem entre si pelo teste de Tukey a $5 \%$ de probabilidade.

Verificou-se que as cultivares que alcançaram os maiores teores de açúcares totais foram as cultivares Pira Ouro $(6,17 \%)$, Jubileu $(5,82 \%)$ e Baia Periforme $(5,64 \%)$, com menores valores para as cultivares Texas Grano $502(4,63 \%)$, Crioula $(4,39 \%)$ e Granex 33 $(4,34 \%)$ (Tabela 2). Para os açúcares redutores, podemse observar teores mais elevados para as cultivares Granex $33(3,55 \%)$ e Texas Grano $502(3,10 \%)$ e menores teores para as cultivares Baia Periforme $(2,24 \%)$ e Pira Ouro $(2,43 \%)$. O sabor e aroma da cebola dependem, entre outros fatores, dos teores de açúcares solúveis redutores e açucares solúveis não-redutores presentes no bulbo (RANDLE, 1992).

Os açúcares não-redutores foram superiores nas cultivares Pira Ouro (3,55\%), Baia Periforme $(3,23 \%)$ e Jubileu $(2,91 \%)$. A cultivar Granex 33 apresentou o pior desempenho $0,74 \%$ (Tabela 2 ). Os açúcares constituem também um dos fatores importantes na qualidade da matéria-prima de cebola. Conforme estudos realizados por Suzuki e Cutcliffe (1989), os carboidratos solúveis não-estruturais constituem entre 41 a $88 \%$ da matéria seca total dos bulbos, dependendo da cultivar. Muitos são os fatores que afetam os teores de açucares solúveis e o potencial de armazenamento da cebola; entretanto, o fator cultivar é um dos mais importantes (SATURNINO e MEDINA, 1980).

Sabendo-se que os bulbos de cebola com elevados teores simultaneamente de sólidos totais e de ácido pirúvico apresentam melhor qualidade para a desidratação, a utilização do índice industrial é o mais adequado para a seleção de cultivares. As cultivares Crioula $(0,87)$ e Baia periforme $(0,75)$ apresentaram os maiores índices industriais, seguidas das cultivares Pira Ouro e Jubileu, com 0,69 e 0,66 , respectivamente. Os menores valores de índice industrial foram para as cultivares Texas Grano $502(0,51)$ e Granex $33(0,32)$.

\section{CONCLUSÕES}

a) As cultivares Pira Ouro, Crioula, Baia Periforme e Jubileu apresentaram os maiores concentrações de sólidos totais e solúveis.

b) A acidez mais elevada ocorreu nas cultivares Crioula e Pira Ouro e a menor foi apresentada pelas cultivares Texas Grano 502 e Granex 33.

c) $\mathrm{O}$ teor de ácido pirúvico foi superior nas cultivares Crioula e Baia Periforme e o menor foi apresentado pela para a cultivar Granex 33 .

d) Os maiores teores de açúcares totais foram alcançados pelas cultivares Pira Ouro, Jubileu e Baia Periforme, e os menores, pelas cultivares Texas Grano 502, Crioula e Granex 33.

e) Os maiores índices industriais foram apresentados pelas cultivares Crioula e Baia Periforme, sendo as mais indicadas para a desidratação. 


\section{REFERÊNCIAS BIBLIOGRÁFICAS}

ASSOCIATION OF OFFICIAL ANALYTICAL CHEMISTS. Official methods of Association of Official Analytical Chemists. 15. ed. Washington, 1990. 684 p.

BRASIL. Ministério da Agricultura e Reforma Agrária. Normas Climatológicas: 1961-1990. Brasília, 1992. 84 p.

CARVALHO, V. D. Características nutricionais, industriais e terapêuticas da cebola. Informe Agropecuário, Belo Horizonte, v. 6, n. 62, p. 71-78, fev. 1980.

CARVALHO, V. D. Efeito da cura na qualidade de algumas cultivares de alho. In: Projeto olericultura: relatório 87/92. Belo Horizonte: EPAMIG, 1993. p. 34-37.

CARVALHO, V. D.; CHALFOUN, S. M.; JUSTE JÚNIOR, E. S. G.; LEITE, I. P. Efeito do tipo de cura na qualidade de algumas cultivares de alho. Pesquisa Agropecuária Brasileira, Brasília, v. 7, n. 22, p. 733 740, jul. 1987.

CASTRO NETTO, P.; SEDIYAMA, G. C.; VILELA, E. A. de. Probabilidade de ocorrência de períodos secos em Lavras, Minas Gerais. Ciência e Prática, Lavras, v. 4 n. 1, p. $45-55,1980$.

CHITARRA, M. I. F. Colheita e pós-colheita de frutos. Informe Agropecuário, Belo Horizonte, v. 17, n. 179, 1994.

CHITARRA, M. I. F.; CHITARRA, A. B. Póscolheita de frutos e hortaliças: fisiologia e manuseio. Lavras: ESAL/FAEPE, 1990. 293 p.

DEBARBA, J. F.; THOMAZELLI, L. F.; GANDIN, C. L.; SILVA, E. Cadeias produtivas do Estado de Santa Catarina: cebola. Florianópolis: EPAGRI, 1998. 115 p. (EPAGRI. Boletim Técnico, 96).
FEIMBERG, B. Vegetables. In: ARSDEL, W. B. V.; COPLEY, M. J.; MORGAN JÚNIOR, A. I. (Eds.). Food Dehydratation. New York: AVI, 1973. v. 2, p. 43-55.

FILGUEIRA, F. A. R. Novo Manual de olericultura: agrotecnologia moderna na produção e comercialização de hortaliças. Viçosa: UFV, 2000. 402 p.

GOMES, F. P. Curso de estatística experimental. 13. ed. São Paulo: Nobel, 1990. 468 p.

PAULA, M. B.; CARVALHO, V. D.; NOGUEIRA, F. D. Efeitos da vinhaça na produção e qualidade da cebola em solo de baixo potencial de produtividade. In: Projeto olericultura: relatório 87/92. Belo

Horizonte: EPAMIG, 1993. p. 190-193.

NELSON, N. A phometric adaptation of Somogy method for determination of glucose. Journal Biological Chemists, Baltimore, n. 153, p. 375, 1944.

RANDLE, W. M. Sulfur nutrition affects nonstructural water-soluble carboidrates in onion germplasm. Hortscience, Alexandria, v. 27, n. 1, p. 52-55, 1992.

SATURNINO, H. M.; MEDINA, P. V. L. Armazenamento de cebola. Informe Agropecuário, Belo Horizonte, n. 62, p. 65-70, fev. 1980.

SCHWIMMER, S.; WESTON, W. J. Enzimatic development of pyruvicacid in onion as a measare of pungency. Journal of Agricultural and Food Chemistry, Washington, v. 4, n. 9, p. 303-304, July/Aug. 1961.

SOUZA, R. J.; RESENDE, G. M. de. Cultura da cebola. Lavras: UFLA, 2002. 115 p. (Textos Acadêmicos Olericultura, 21).

SUZUKI, M.; CUTCLIFFE, J. A. Fructans in onion bulbs in relation to storage life. Canadian Journal Plant Science, Ottawa, n. 69, p. 1327-1333, 1989. 